\title{
Metastasis-associated protein 1 enhances angiogenesis by stabilization of HIF-1a
}

\author{
HYO-EUN MOON ${ }^{1}$, HWANJU CHEON ${ }^{1}$, KWANG-HOON CHUN ${ }^{2}$, SEUNG KI LEE ${ }^{2}$, YONG-SIK KIM ${ }^{3}$, \\ BO-KYUNG JUNG ${ }^{2}$, JEONG AE PARK ${ }^{2}$, SE-HEE KIM ${ }^{2}$, JOO-WON JEONG ${ }^{4}$ and MYUNG-SHIK LEE ${ }^{1}$ \\ ${ }^{1}$ Department of Medicine, Samsung Medical Center, Sungkyunkwan University School of Medicine; ${ }^{2}$ Division of \\ Pharmaceutical Biosciences, College of Pharmacy, Seoul National University; ${ }^{3}$ Cell Biology Section, Division of \\ Intramural Research, National Institute of Environmental Health Science/NIH, Research Triangle Park, NC, USA; \\ ${ }^{4}$ Department of Anatomy, MRC for ROS, School of Medicine, Kyung-Hee University, Seoul, Korea
}

Received June 7, 2006; Accepted July 17, 2006

\begin{abstract}
Metastasis-associated protein 1 (MTA1) is highly upregulated in cancer cells with metastatic potential; however, the molecular mechanism by which MTA1 increases the metastatic potential of cancer cells is unknown. We characterized the functional consequences of MTA1 overexpression in cancer cells with an emphasis on its potential role as a deacetylator of hypoxia-inducible factor- $1 \alpha$ (HIF-1 $\alpha)$. MTA1 increased the expression of HIF- $1 \alpha$ protein, but did not increase the expression of its mRNA. Glutathione $S$-transferase pulldown and coimmunoprecipitation assays demonstrated direct interaction of MTA1 with HIF-1 $1 \alpha$ both in vitro and in vivo. Immunoprecipitation and acetylation assays also showed that MTA1 has deacetylation activity on HIF-1 $\alpha$ in vivo. Moreover, MTA1 increased the transcriptional activity of HIF-1 $\alpha$ and enhanced the expression of vascular endothelial growth factor, a target molecule of HIF-1 $\alpha$. Conditioned medium collected from MTA1 transfectants also increased angiogenesis in vitro and in vivo, probably through enhanced HIF-1 $\alpha$ stabilization. These results indicate that MTA1 enhances angiogenesis by stabilization of the HIF- $1 \alpha$ protein, which is closely related to the increased metastatic potential of cancer cells with high MTA1 expression.
\end{abstract}

Correspondence to: Dr Myung-Shik Lee, Department of Medicine, Samsung Medical Center, Sungkyunkwan University School of Medicine, 50 Irwon-dong, Kangnam-Ku, Seoul 135-710, Korea

E-mail: mslee@smc.samsung.co.kr

Abbreviations: MTA1, metastasis-associated protein 1; HIF-1 $\alpha$, hypoxia-inducible factor- $1 \alpha$; ARD1, arrest defective protein 1; VEGF, vascular endothelial growth factor; HRE, hypoxia response element; HDAC, histone deacetylase; GST, Glutathione S-transferase; pVHL, von Hippel-Lindau tumor suppressor gene product; RT-PCR, reverse transcription-polymerase chain reaction

Key words: MTA1, HIF-1 $\alpha$, stabilization, angiogenesis

\section{Introduction}

MTA1 was originally isolated by differential expression screening of metastatic cell lines with high and low metastatic potentials (1). While increased expression of MTA1 in highly metastatic cells has been confirmed $(2,3)$, the precise mechanism by which MTA1 increases the metastatic potential of cancer cells is currently unknown. In vitro studies have shown that MTA1 increases invasiveness and migration (4); however, increased invasiveness alone cannot explain its potential role in metastasis. A recent report suggested that MTA1 may possibly be involved in the regulation of gene expression by covalent modification of histone proteins (5). Consistent with this notion, MTA proteins physically interact with histone deacetylases (HDAC1 and HDAC2) and constitute the nucleosome remodeling histone deacetylation (NuRD) complex, playing a role in histone deacetylation and transcriptional control $(6,7)$. MTA2 has also been reported to have deacetylation activity on both histone and non-histone proteins, such as p53 $(5,8)$. Thus, MTA1 could possibly have deacetylation activity as well. According to a previous report that HDAC induces angiogenesis (9), the deacetylation activity of MTA homologues may potentially be important in regulation of angiogenesis or metastasis. Moreover, it was reported that mouse ARD1 acetylates and destabilizes HIF$1 \alpha$, suggesting that reversible acetylation influences the stability of HIF- $1 \alpha(10,11)$. HIF- $1 \alpha$ is a subunit of HIF-1 which is a master transcription factor mediating cellular and systemic homeostatic responses to reduced $\mathrm{O}_{2}$ availability, especially in angiogenesis. In particular, HIF-1 $\alpha$ is one of the critical regulators for the hypoxia-induced angiogenesis of tumor tissues (12). Under normoxia, HIF-1 $\alpha$ is rapidly degraded by the ubiquitin-proteasome pathway through its interaction with the von Hippel-Lindau tumor suppressor gene product (pVHL) $(13,14)$ while HIF-1 $\alpha$ becomes stable under hypoxia. Therefore, the investigations of the effects of MTA 1 on HIF- $1 \alpha$ may provide an important clue to understand the mechanism of the increased metastasis of cancer cells with high MTA1 expression. In this study, we found that MTA1 enhances angiogenesis by stabilization of HIF- $1 \alpha$. 


\section{Materials and methods}

Reagents and antibodies. MG132 and G418 were purchased from Calbiochem (Darmstadt, Germany) and Invitrogen (Carlsbad, CA), respectively. Protein G-agarose, protease inhibitor cocktail, and Fugene 6 reagent were from Roche (Mannheim, Germany). Glutathione Sepharose ${ }^{\mathrm{TM}}$ 4B was purchased from Amersham Biosciences (Uppsala, Sweden). Antibodies to HIF-1 $\alpha$, FLAG and GFP were obtained from BD Biosciences (San Diego, CA), Sigma (St. Louis, MO), and Clontech (Palo Alto, CA), respectively. Antibodies to VEGF, $B$-actin and anti-Ac-Lys antibodies were purchased from Santa Cruz Biotechnology (Santa Cruz, CA), and Upstate Biotechnology (New York, NY), respectively.

Plasmids and recombinant proteins. To construct GFP-ARD1, the mouse ARD1225 cDNA was inserted into a prokaryotic expression vector, $\mathrm{pCS}^{+}(10,11)$. To make an inducible GST-MTA1 construct, the MTA1 cDNA was inserted into a prokaryotic expression vector, pGEX-4T (Amersham Pharmacia Biotech).

RT-PCR analysis. Total-RNA from cells was isolated using TRIzol ${ }^{\circledR}$ reagent (Invitrogen), and RT-PCR was carried out as previously described (10). Specific primer sets were used for HIF- $1 \alpha$ (sense 5'-CTGACCCTGCACTCAATCAA-3', antisense 5'-CTTTGAGGACTTGCGCTTTC-3'), VEGF (sense 5'-GAGAATTCGGCCTCCGAAACCATGAACTTTCT GCT-3', antisense 5'-GAGCATGCCCTCCTGCCCGGCTC ACCGC-3'), MMP-2 (sense 5'-GCGACAAGAAGTATGGC TTC-3', antisense 5'-TGCCAAGGTCAATGTCAGGA-3'), and $\beta$-actin (sense 5'-GGCATCCACGAAACTACCTT-3', antisense 5'-CTGTGTGGACTTGGGAGAGG-3').

GST pull-down assay. $\left[{ }^{35} \mathrm{~S}\right] \mathrm{Methionine-labeled} \mathrm{in} \mathrm{vitro} \mathrm{trans-}$ lated full length of HIF-1 $\alpha$ was prepared using the TNT system (Promega, Madison, WI). GST-fusion proteins were prepared as previously described (10). The GST pull-down assay was carried out using GST or GST-MTA1 recombinant protein and in vitro translated full-length HIF- $1 \alpha$ as previously described $(10,15)$.

Cell culture and hypoxic condition. H1299 and SK-Hep1 cells were maintained in Dulbecco's modified Eagle's medium (DMEM, Cambrex, Baltimore, MD) supplemented with $10 \%$ fetal bovine serum (FBS, Cambrex), $1 \%$ antibiotics and $1 \%$ glutamine at $37^{\circ} \mathrm{C}$ in a $5 \% \mathrm{CO}_{2}$ standard incubator. Primary human umbilical vascular endothelial cells (HUVECs, passages 2-5) were grown on $0.1 \%$ gelatin-coated plates in M199 supplemented with $20 \% \mathrm{FBS}, 50 \mu \mathrm{g} / \mathrm{ml}$ endothelial cell growth supplement, and 15 units $/ \mathrm{ml}$ heparin. To generate mock and stable MTA1 transfectants, H1299 and SK-Hep1 cells were transfected with empty pcDNA3.1 or pcDNA3.1-human MTA1-FLAG and were selected using G418 sulfate (500$600 \mu \mathrm{g} / \mathrm{ml}$ ). For hypoxic culture, cells were maintained in 5\% $\mathrm{CO}_{2}$ and $1 \% \quad \mathrm{O}_{2}$ balanced with $\mathrm{N}_{2}$ using a hypoxic chamber (ASTEC).

Preparation of conditioned media. H1299 mock or stable MTA1 transfectants were seeded and incubated in 1\% FBS
DMEM for $24 \mathrm{~h}$. For the tube formation assay, conditioned medium (CM) was filtered through $0.22 \mu \mathrm{M}$ pore membranes (Millipore, Bedford, MA) and was then applied to HUVECs. For the chorioallantoic membrane (CAM) assay, cells were incubated in serum-free DMEM for $24 \mathrm{~h}$, and the supernatant was concentrated using an ultrafiltration kit (3-kDa cut-off, Millipore).

In vivo acetylation assay. MG132 $(10 \mu \mathrm{M})$ was added to H1299 cells transiently or stably transfected with appropriate expression vectors. Total cell extract was immunoprecipitated with $1 \mu \mathrm{g}$ Ac-Lys (acetyl-lysine) antibody. The immunoprecipitate was subjected to SDS-PAGE and Western blotting using anti-HIF- $1 \alpha$ antibody.

Coimmunoprecipitation assay. After transient transfection of mock or stable MTA1 transfectants with GFP-HIF-1 $\alpha$, cells were maintained for 4-6 $\mathrm{h}$ in hypoxic and normoxic conditions prior to harvesting. Preparation of protein extract, immunoprecipitation and Western blotting were performed as previously described $(10,15)$.

Reporter assay. pSV40 promoter-Epo-HRE-Luc reporter, pBOS-hHIF- $1 \alpha$ and pBOS-hHIF-1ß together with MTA1FLAG were transfected into H1299 and SK-Hep1 cells using Fugene 6 reagent. After incubation in hypoxic and normoxic conditions, cell lysate was assayed for luciferase activity using the Dual-Luciferase ${ }^{\circledR}$ Reporter assay system (Promega) and a luminometer. The relative luciferase activities were calculated as previously described $(10,15)$.

Tube formation assay and CAM assay. Matrigel $(10 \mathrm{mg} / \mathrm{ml})$ was polymerized for $30 \mathrm{~min}$ at $37^{\circ} \mathrm{C}$. HUVECs $\left(1.5 \times 10^{5}\right)$ were seeded on the matrigel and grown in CMs. After $24 \mathrm{~h}$ of incubation, cells were photographed at x 40 magnification. Tube length was determined using an inverted microscope equipped with a digital CCD camera (Zeiss) and was quantified using Image Lab imaging software (MCM Design). The CAM assay was conducted using 9-9.5-day-old chick embryos as previously described (15).

\section{Results}

Increased HIF-1a expression by MTA1. MTA1 has been reported to possess HDAC activity (5), and acetylation of HIF- $1 \alpha$ was shown to modulate the stability of HIF-1 $\alpha$ (10). We therefore hypothesized that MTA1 is capable of deacetylating HIF- $1 \alpha$, and subsequently modulates the HIF- $1 \alpha$ stability that could potentially be associated with an increased metastatic potential of cancer cells expressing MTA1. Thus, we overexpressed MTA1 in H1299 human non-small cell lung cancer (NSCLC) cells and explored the regulation of HIF-1 $\alpha$ protein in hypoxic conditions. The HIF-1 $\alpha$ protein level was remarkably upregulated in $\mathrm{H} 1299$ cells stably transfected with an MTA1 expression vector (lane 4) (Fig. 1A). However, MTA1 overexpression did not affect its mRNA level, which suggests that the increase in the HIF-1 $\alpha$ level by MTA1 is not due to upregulation of its transcripts, but is instead due to post-translational regulation (Fig. 1A). Another transfectant, SK-Hep1 hepatoma cells stably overexpressing MTA1, also 

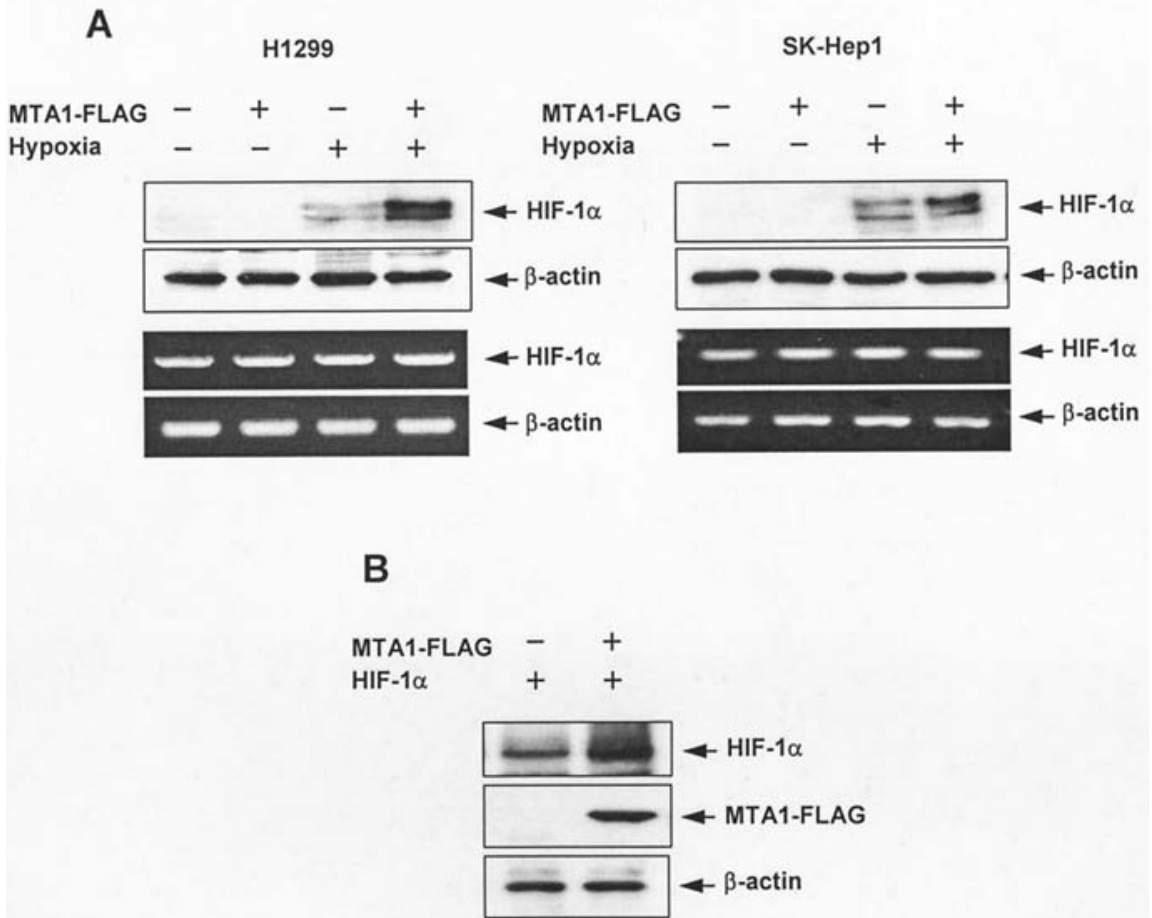

Figure 1. MTA1 increases HIF-1 $\alpha$ stability. (A) Left, H1299 cells were stably transfected with the indicated expression vector and left untreated or exposed to $1 \% \mathrm{O}_{2}$ (hypoxia) for $4 \mathrm{~h}$. Right, SK-Hep1 cells were stably transfected with the indicated expression vector, and the same experiment was carried out. The expression of the HIF-1 $\alpha$ and $\beta$-actin proteins was examined by Western blotting using anti-HIF-1 $\alpha$ and - $\beta$-actin antibodies (upper). RT-PCR analysis was carried out using specific primer sets for HIF-1 $\alpha$ and $\beta$-actin (lower). (B), Mock-H1299 and MTA1-H1299 cells were transfected with pBOS-hHIF-1 $\alpha$. The expression of the HIF-1 $\alpha$, MTA1-FLAG and $\beta$-actin proteins was examined by Western blotting using anti-HIF-1 $\alpha$,-FLAG and - $\beta$-actin antibodies .

showed increased HIF-1 $\alpha$ protein expression in hypoxic conditions compared to mock transfectants (lane 4), indicating that MTA1-induced increases in HIF-1 $\alpha$ protein expression are not restricted to a single cell type (Fig. 1A). Increased HIF-1 $\alpha$ protein expression in H1299 stable MTA1 transfectants was observed even in normoxic conditions when HIF-1 $\alpha$ was overexpressed by transient transfection (lane 2) (Fig. 1B).

Interaction between MTAl and HIF-1a protein. To explain the increased protein expression of HIF-1 $\alpha$ by MTA1, we studied a possible physical interaction between HIF-1 $\alpha$ and MTA1 using coimmunoprecipitation assay. When MTA1 transfectants were transiently transfected with GFP-HIF-1 $\alpha$ to enhance the expression level of HIF-1 $\alpha$ (10), both exogenous GFP-HIF- $1 \alpha$ and endogenous HIF- $1 \alpha$ proteins were detected in anti-FLAG immunoprecipitates in hypoxic conditions (lane 4), indicating in vivo binding of MTA1 with HIF-1 $\alpha$ (Fig. 2A). We also studied whether MTA1 directly binds HIF-1 $\alpha$ in vitro using GST-pull-down assay. As shown in Fig. 2B, in vitro translated HIF-1 $\alpha$ was pulled down by GSTfused MTA1, suggesting direct interaction of HIF-1 $\alpha$ with MTA1 (lane 1).

Deacetylation of HIF-1a protein by MTAl. Since MTA1 is a component of HDAC complexes and MTA2, a homologue of MTA1, has deacetylation activity $(5,8)$, we investigated whether MTA1 affects the acetylation of HIF-1 $\alpha$ which is capable of modulating its stability (10). Western blotting using HIF- $1 \alpha$ antibody after immunoprecipitation with anti-Ac-Lys antibody showed that the intracellular level of acetylated
A

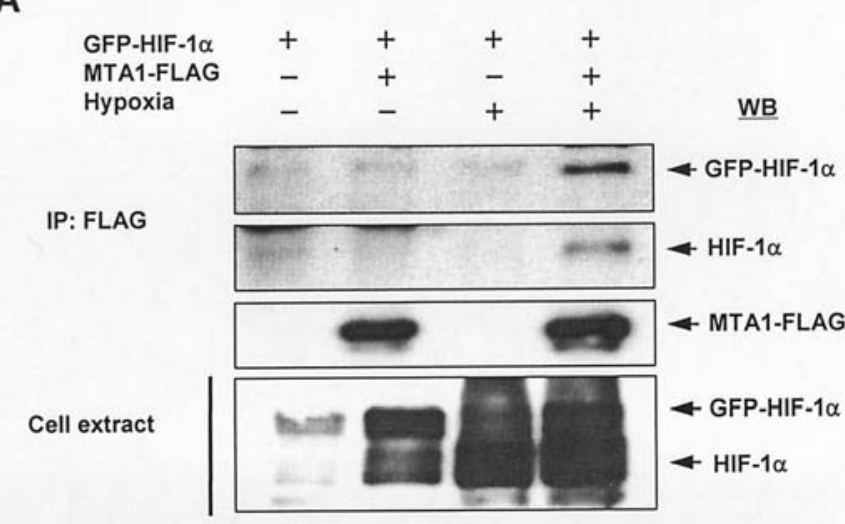

B

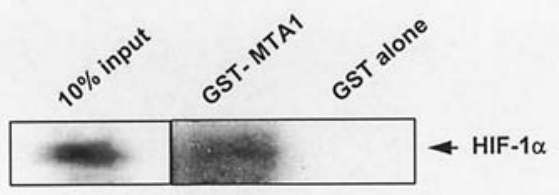

Figure 2. MTA1 interacts with HIF-1 $\alpha$ in vitro and in vivo. (A), Mock-H1299 and MTA1-H1299 cells were transiently transfected with GFP- or GFP-HIF-1 $\alpha$ as indicated, and cells were then left untreated or exposed to hypoxic conditions for $4 \mathrm{~h}$. Total cell lysate was immunoprecipitated with anti-FLAG antibody. The immunoprecipitates were analyzed by Western blotting using anti-HIF- $1 \alpha$ and -FLAG antibodies. The presence of GFP-HIF-1 $\alpha$ and endogenous HIF- $1 \alpha$ was examined using anti-HIF- $1 \alpha$ antibody. Immunoprecipitation (IP); Western blotting (WB). (B), Full-length HIF-1 $\alpha$ was translated in the presence of $\left[{ }^{35} \mathrm{~S}\right]$ methionine and mixed with GST- or GSTMTA1-bound beads. Ten percent of the material used as a control in this assay. 

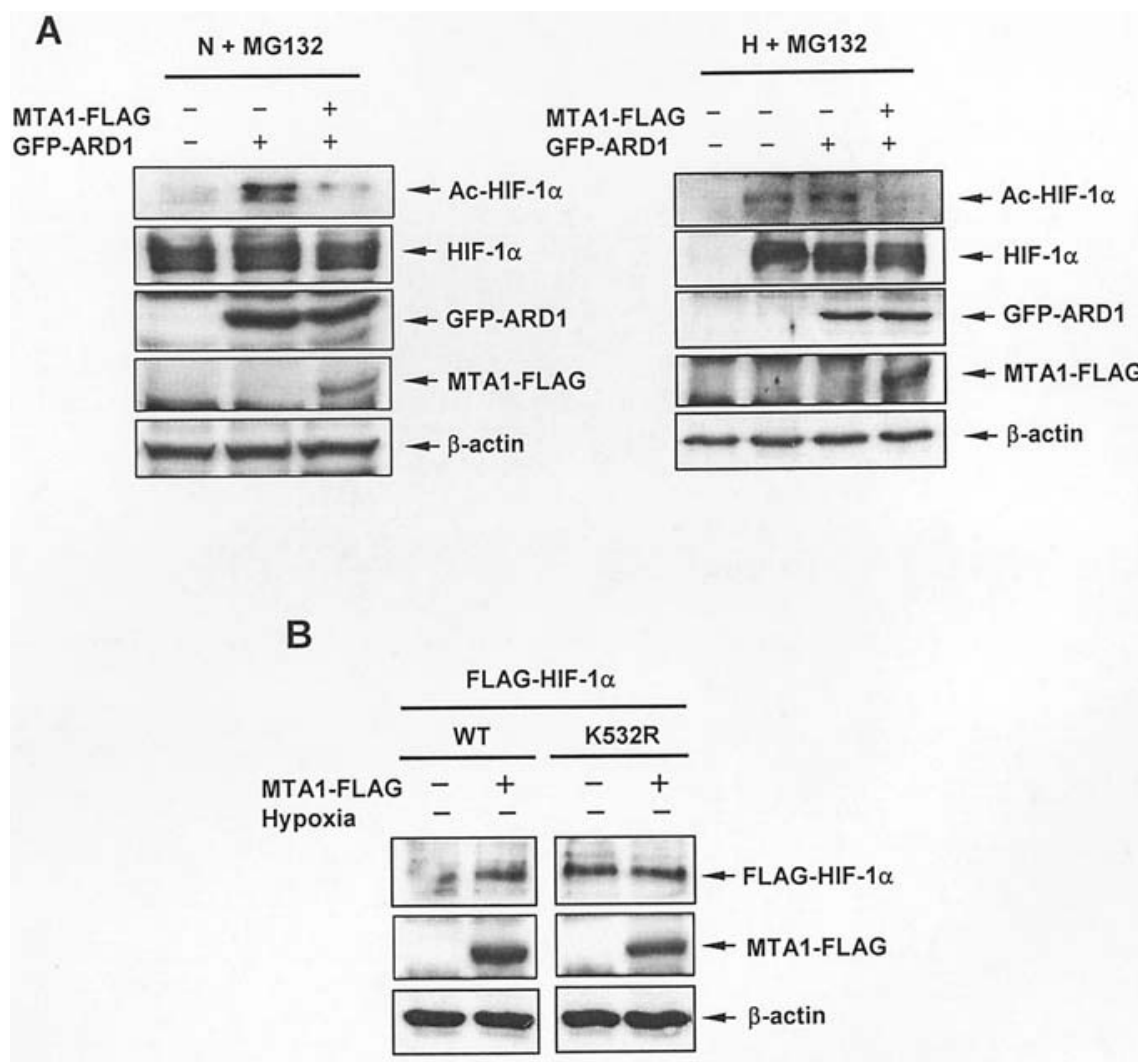

Figure 3. MTA1 decreases the mARD1 ${ }^{225}$-mediated acetylation level of HIF-1 $\alpha$ in vivo. (A), H1299 cells were transfected with GFP-ARD1 (GFP-mARD1225) together with MTA1-FLAG or empty vector as indicated and treated with $10 \mu \mathrm{M} \mathrm{MG} 132$ in normoxic (left) or hypoxic (right) conditions for 8 h. Extract was immunoprecipitated with anti-Ac-Lys antibody, and the immunoprecipitate was subjected to SDS-PAGE and Western blotting using anti-HIF-1 $\alpha$ antibody. The expression of HIF-1 $\alpha$, GFP-ARD1, MTA1-FLAG and $\beta$-actin was examined by Western blotting using anti-HIF-1 $\alpha$-GFP, -FLAG and - $\beta$-actin antibodies. (B), HEK293 cells were transfected with FLAG-HIF-1 $\alpha$ (WT) or FLAG-HIF-1 $\alpha$ K532R (K532R) together with MTA1-FLAG or empty vector as indicated in normoxic condition. The expression of the FLAG-HIF-1 $\alpha$, MTA1-FLAG and B-actin proteins was examined by Western blotting using antiFLAG and - $\beta$-actin antibodies.

HIF-1 $\alpha$ was decreased in MTA1 transfectants compared to mock transfectants in the presence of MG132, an inhibitor of HIF-1 $\alpha$ degradation (data not shown). This finding suggests that MTA1 decreases the acetylation level of HIF-1 $\alpha$ thereby leading to increased HIF-1 $\alpha$ stability. To confirm our findings using cells with higher levels of acetylated HIF-1 $\alpha$, we conducted the same experiment after transfection with GFPmARD $1^{225}$, which acetylates HIF- $1 \alpha(10,11)$. In this condition, we observed more prominent bands of acetylated HIF-1 $\alpha$ and the level of acetylated HIF-1 $\alpha$ was markedly decreased in H1299 cells transiently transfected with mARD $1^{225}$ and MTA1 in the presence of MG132 both normoxic (lane 3, left) and hypoxic (lane 4, right) conditions compared to ARD1 and mock transfection, further supporting deacetylation of HIF-1 $\alpha$ by MTA1 (Fig. 3A). Next, to confirm the deacetylation activity of MTA1 employing a HIF-1 $\alpha$ mutant lacking ARD1-dependent acetylation site, we conducted transiently transfection of HEK293 cells with FLAG-HIF-1 $\alpha$ (WT) or FLAG-HIF-1 $\alpha$ (K532R) (10) together with MTA1-FLAG in normoxic condition (Fig. 3B). The K532R mutant was stably expressed in normoxic condition, as previously reported $(10,23)$. The expression of wild-type HIF-1 $\alpha$ was increased by MTA1, whereas that of K532R mutant was not, suggesting that Lys532 is probably the site that regulates the stability of HIF- $1 \alpha$ through deacetylation by MTA1.
MTAl increases the transactivation activity mediated by $H I F-1$. To study whether deacetylation of HIF-1 $\alpha$ and its increased stability by MTA1 affect the transcriptional activity of HIF-1 $\alpha$, we conducted a reporter assay using a construct containing the hypoxia response element (HRE). In both normoxic and hypoxic conditions, the EpoHRE reporter activity was significantly increased in the stable MTA1 transfectants compared to mock transfectants (Fig. 4A). Next, we investigated whether deacetylation and stabilization of HIF-1 $\alpha$ by MTA1 lead to the induction of vascular endothelial growth factor (VEGF), as HIF-1 $\alpha$ target protein, which is directly involved in angiogenesis and metastasis (16). The expression of VEGF was substantially increased at the mRNA and protein levels by MTA1 in hypoxia (lane 4) (Fig. 4B). Additionally, the expression of matrix metalloproteinase (MMP)-2, that promotes invasive cancer phenotypes in an HIF- $1 \alpha$-dependent manner $(4,17)$, was also increased in H1299 stable MTA1 transfectants (lane 2) (Fig. 4C).

MTA1 overexpression induces angiogenesis. In an attempt to investigate the biological consequences of HIF- $1 \alpha$ deacetylation and stabilization by MTA1, we then conducted in vitro tube formation and in vivo CAM assays. The tube formation assay showed that CM collected from MTA1 transfectants induced an increased formation of the organized network of 
A

H1299

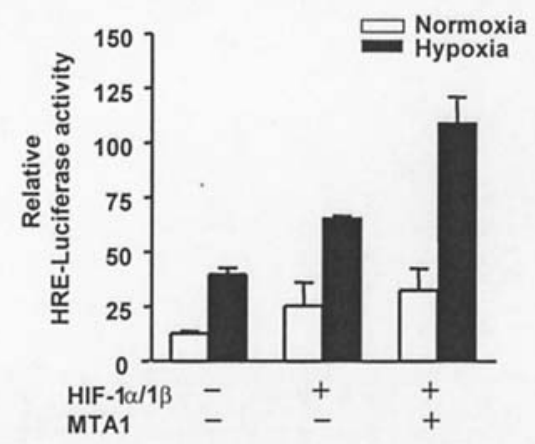

B
H1299

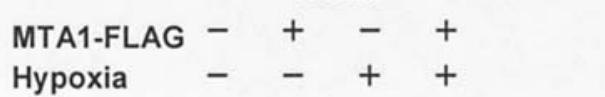

Hyрoxia $-\quad++$
SK-Hep1

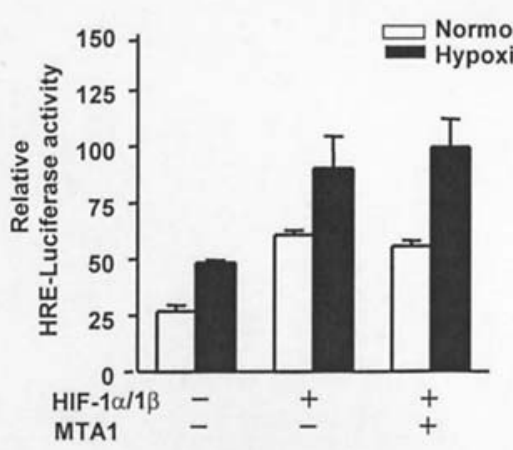

\section{SK-Hep1}

MTA1-FLAG - +-+

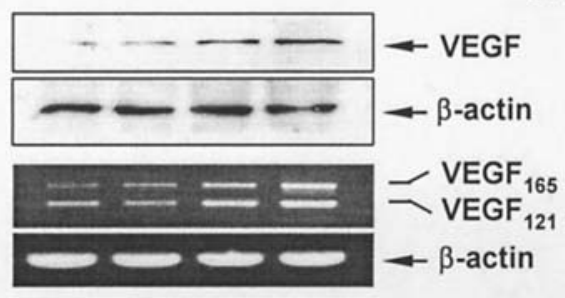

C

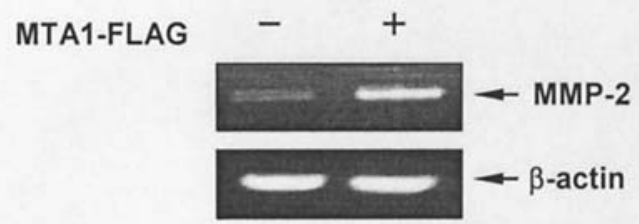

E

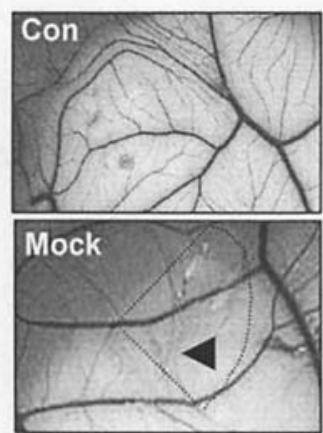

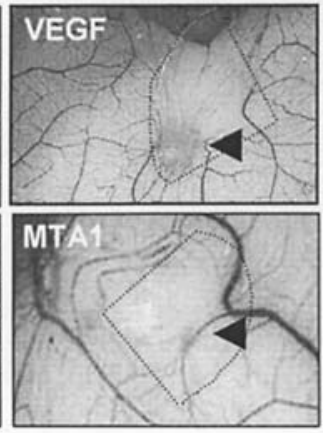

D
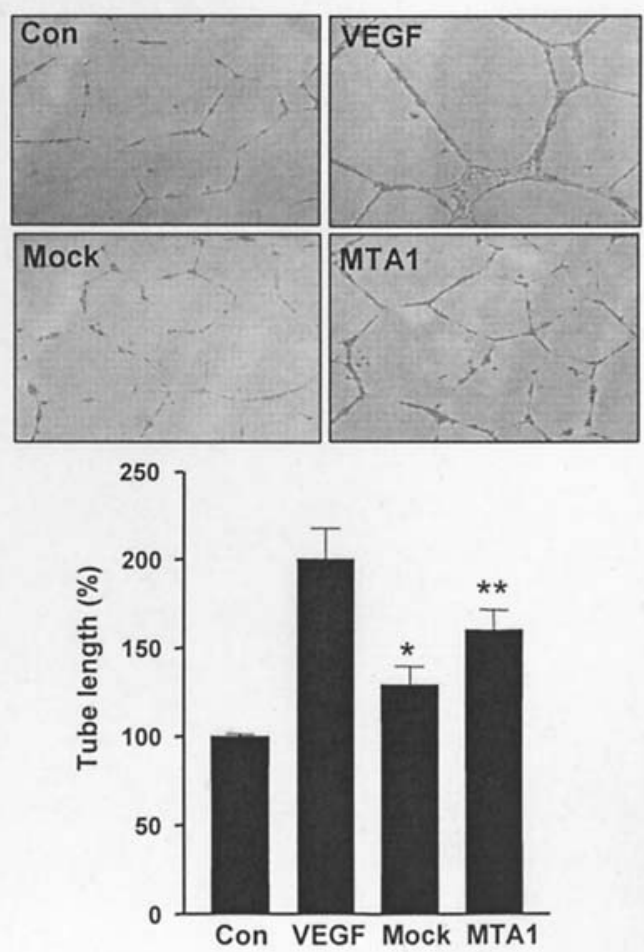

Figure 4. MTA1 enhances VEGF expression and angiogenesis. (A) Left, H1299 cells were transfected with pSV40pro-Epo-HRE-Luc ( $1 \mu \mathrm{g})$, pBOS-hHIF-1 $\alpha$ $(\mathrm{HIF}-1 \alpha)(0.1 \mu \mathrm{g})$ and pBOS-hHIF-1 $\alpha$ (HIF-1 $\alpha)(0.1 \mu \mathrm{g})$ with MTA1-FLAG (MTA1) or empty vector as indicated. Transfected cells were incubated at $21 \%$ $\mathrm{O}_{2}$ (normoxia) for $24 \mathrm{~h}$, and were then incubated in normoxic or hypoxic conditions for additional $24 \mathrm{~h}$. Right, the same experiment was carried out using SK-Hep1 cells. (B), Mock- and MTA1-transfected cells were left untreated or exposed to hypoxic conditions for $16 \mathrm{~h}$ (H1299; left) or 8 h (SK-Hep1; right) cells. VEGF and $\beta$-actin protein expressions were examined by Western blotting using anti-VEGF and - $\beta$-actin antibodies (upper). RT-PCR analysis was carried out using primer sets specific for VEGF and B-actin (lower). (C), Mock-H1299 and MTA1-H1299 cells were left in normoxic conditions and RT-PCR analyses were carried out using primer sets specific for MMP-2 and B-actin. (D), CMs were collected from non-transfected (Con), mock-transfected (Mock), or MTA1-transfected H1299 cells (MTA1) cultured in DMEM 1\% FBS for $24 \mathrm{~h}$. HUVECs on matrigel were grown in the CM for $24 \mathrm{~h}$. VEGF (20 ng/ml) was employed as a positive control. Tube length was quantified and expressed as the means $\pm \mathrm{SD}(\mathrm{n}=4)$. $\left({ }^{*} \mathrm{P}<0.05\right.$ and ${ }^{* *} \mathrm{P}<0.01$ compared to control by unpaired t-test). Con was set as $100 \%$. (E), Concentrated CM (100-fold) was added to CAM surface of 9-day-old chick embryos. After 3 days of incubation, the eggs were observed on a microscope. The eggs were treated with CMs collected from non-transfected (Con), mock-transfected (Mock), or MTA1-transfected H1299 cells (MTA1) cultured in DMEM 1\% FBS for $24 \mathrm{~h}$. VEGF $(50 \mathrm{ng} / \mathrm{ml})$ was employed as a positive control. Arrowheads indicate a spoke-wheel-like vascular zone on CM-coated coverslips (dotted line). 
endothelial cells on matrigel compared to control $\mathrm{CM}$ or mock CM (Fig. 4D). The CAM assay also demonstrated that the concentrated CM (100-fold) collected from MTA1 transfectants had a significantly higher angiogenic activity than that collected from control or mock transfectants (Fig. 4E), indicating that the increased stability of HIF-1 $\alpha$ by MTA1 leads to the increased angiogenesis.

\section{Discussion}

To understand the mechanism by which MTA1 increases the metastatic potential of cancer cells, we studied the functional consequences of MTA1 overexpression with an emphasis on non-histone protein HIF- $1 \alpha$, which is potentially associated with metastasis. Although MTA2 has been reported to have deacetylation activity on p53 (9) and MTA1 has a high sequence homology with MTA2, MTA2 has not been shown to be involved in metastasis or carcinogenesis (5). The regulation of HIF-1 $\alpha$ stability and activity occurs at multiple levels. In particular, the modulations of HIF- $1 \alpha$ protein by its interaction with other proteins are important for stabilization and activation of HIF-1 $\alpha$ protein $(10,17)$.

The expression of HIF-1 $\alpha$ protein was enhanced in stable MTA1 transfectants of H1299 and SK-Hep1 cells in both normoxic and hypoxic conditions, but the expression of its mRNA was not. These findings suggest that MTA1 increases the stability of HIF-1 $\alpha$. Moreover, we demonstrated that MTA1 interacts with HIF-1 $\alpha$ both in vitro and in vivo. Several proteins, particularly those in transcriptional complexes, such as MICoA or NRIF3, have been reported to interact with MTA1 $(18,19)$.

Acetylation is a key posttranslational modification of many proteins, and is responsible for the regulation of a number of critical intracellular pathways (20). In this investigation, we found that MTA1 dramatically decreased the mouse ARD1mediated acetylation level of HIF-1 $\alpha$ in vivo in both normoxic and hypoxic conditions, and concluded that MTA1 deacetylates HIF-1 $\alpha$. During this investigation, papers reporting that human ARD $1^{235}$ does not affect HIF- $1 \alpha$ stability or acetylation were published $(21,22)$. However, Kim et al identified several ARD1 variants that have different effects on stability and acetylation of HIF- $1 \alpha$ which may reflect the difference between species or that between various isoforms (11). Moreover, very recently, Yoo et al reported that human MTA1 enhances stability of HIF- $1 \alpha$ by recruiting HDAC1 (23). These results indicated that acetylation is the major target of MTA1/HDAC1 function. Our results shown in Fig.3A also demonstrated that MTA1 deacetylates HIF-1 $\alpha$ in vivo probably mediated by HDAC1 recruitment. Thus, such deacetylation by MTA1 blocks the degradation pathway such as hydroxylation and ubiquitination (23). Furthermore, we found that MTA1 enhances the expression of VEGF by increasing the transcriptional activity of HIF-1 $\alpha$. Because of the induction of angiogenic molecules such as VEGF, CMs collected from MTA1 transfectants increased angiogenesis both in vitro and in vivo.

Collectively, our data suggest that MTA1 is an active angiogenic regulator that deacetylates HIF- $1 \alpha$ through direct interaction, and also plays a critical role in the stabilization of HIF-1 $\alpha$. By characterizing further target molecules of MTA1, particularly in relation to its deacetylating activity, we will be able to understand the mechanism by which MTA1 or other metastasis genes confer metastatic behaviors, the ultimate cancer phenotype. Approaches aiming at the regulation of the acetylation status of angiogenic or carcinogenic molecules may provide a novel strategy for cancer therapy in the future.

\section{Acknowledgements}

This study was supported by the Nano/Bio Science Program Grant (2004-00716), and 21C Frontier Functional Proteomics Project (FPR05C1-160). M.-S.L. is an awardee of the SRC Grants/R01-2005-000-10326-0 from the Korea Science and Engineering Foundation. We thank Professor Kyu-Won Kim (College of Pharmacy, Seoul National University) for providing us with GFP-ARD1, GFP-HIF-1 $\alpha$, FLAG-HIF-1 (WT), FLAG-HIF-1 (K532R), Professor Paul A. Wade (Department of Pathology and Laboratory Medicine, Emory University School of Medicine, USA) for human MTA1-FLAG, and also thank Dr Y. Fujii-Kuriyama (Department of Biomolecular Sciences, Graduate School of Life Science, Tohoku University, Sendai, Japan) for pBOS-hHIF-1 $\alpha$, pBOS-hHIF-1ß and pSV40pro-Epo-HRE-Luc vectors.

\section{References}

1. Toh Y, Pencil SD and Nicolson GL: A novel candidate metastasisassociated gene, mta1, differentially expressed in highly metastatic mammary adenocarcinoma cell lines. cDNA cloning, expression and protein analyses. J Biol Chem 269: 2295822963, 1994

2. Toh Y, Oki E, Oda S, Tokunaga E, Ohno S, Maehara Y, Nicolson GL and Sugimachi K: Overexpression of the MTA1 gene in gastrointestinal carcinomas: correlation with invasion and metastasis. Int J Cancer 74: 459-463, 1997.

3. Hofer MD, Kuefer R, Varambally S, Li H, Ma J, Shapiro GI, Gschwend JE, Hautmann RE, Sanda MG, Giehl K, Menke A, Chinnaiyan AM and Rubin MA: The role of metastasis-associated protein 1 in prostate cancer progression. Cancer Res 64: 825-829, 2004.

4. Mahoney MG, Simpson A, Jost M, Noe M, Kari C, Pepe D, Choi YW, Uitto J and Rodeck U: Metastasis-associated protein (MTA) 1 enhances migration, invasion and anchorage-independent survival of immortalized human keratinocytes. Oncogene 21: 2161-2170, 2002.

5. Yao YL and Yang WM: The metastasis-associated proteins 1 and 2 form distinct protein complexes with histone deacetylase activity. J Biol Chem 278: 42560-42568, 2003.

6. Xue Y, Wong J, Moreno GT, Young MK and Wang W: NURD, a novel complex with both ATP-dependent chromatinremodeling and histone deacetylase activities. Mol Cell 2: 851861, 1998.

7. Bowen NJ, Fujita N, Kajita M and Wade PA: Mi-2/NuRD: multiple complexes for many purposes. Biochim Biophys Acta 1677: 52-57, 2004.

8. Luo J, Su F, Chen D, Shiloh A and Gu W: Deacetylation of p53 modulates its effect on cell growth and apoptosis. Nature 408: 377-381, 2000.

9. Kim MS, Kwon HJ, Lee YM, Baek JH, Jang JE, Lee SW, Moon EJ, Kim HS, Lee SK, Chung HY, Kim CW and Kim KW: Histone deacetylases induce angiogenesis by negative regulation of tumor suppressor genes. Nat Med 7: 437-443, 2001.

10. Jeong JW, Bae MK, Ahn MY, Kim SH, Sohn TK, Bae MH, Yoo MA, Song EJ, Lee KJ and Kim KW: Regulation and destabilization of HIF-1 $\alpha$ by ARD1-mediated acetylation. Cell 111: 709-720, 2002.

11. Kim SH, Park JA, Kim JH, Lee JW, Seo JH, Jung BK, Chun KH, Jeong JW, Bae MK and Kim KW: Characterization of ARD1 variants in mammalian cells. Biochem Biophys Res Commun 340: 422-427, 2005.

12. Kim KR, Moon HE and Kim KW: Hypoxia-induced angiogenesis in human hepatocellular carcinoma. J Mol Med 80: 703-714, 2002. 
13. Jaakkola P, Mole DR, Tian YM, Wilson MI, Gielbert J, Gaskell SJ, Kriegsheim Av, Hebestreit HF, Mukherji M, Schofield CJ, Maxwell PH, Pugh CW and Ratcliffe PJ: Targeting of HIF- $\alpha$ to the von Hippel-Lindau ubiquitination complex by $\mathrm{O}_{2}$-regulated prolyl hydroxylation. Science 292: 468-472, 2001.

14. Ohh M, Park CW, Ivan M, Hoffman MA, Kim TY, Huang LE, Pavletich N, Chau V and Kaelin WG: Ubiquitination of hypoxiainducible factor requires direct binding to the beta-domain of the von Hippel-Lindau protein. Nat Cell Biol 2: 423-427, 2000.

15. Moon EJ, Jeong CH, Jeong JW, Kim KR, Yu DY, Murakami S, Kim CW and Kim KW: Hepatitis B virus X protein induces angiogenesis by stabilizing hypoxia-inducible factor- $1 \alpha$. FASEB J 18: 382-384, 2004.

16. Tammela T, Enholm B, Alitalo K and Paavonen K: The biology of vascular endothelial growth factors. Cardiovasc Res 65: 550-563, 2005.

17. Krishnamachary B, Berg-Dixon S, Kelly B, Agani F, Feldser D, Ferreira G, Iyer N, La Rusch J, Pak B, Taghavi P and Semenza GL: Regulation of colon carcinoma cell invasion by hypoxia-inducible factor 1 . Cancer Res 63: 1138-1143, 2003.
18. Mishra SK, Mazumdar A, Vadlamudi RK, Li F, Wang RA, Yu W, Jordan VC, Santen RJ and Kumar R: MICoA, a novel metastasisassociated protein 1 (MTA1) interacting protein coactivator, regulates estrogen receptor-alpha transactivation functions. J Biol Chem 278: 19209-19219, 2003.

19. Talukder AH, Gururaj A, Mishra SK, Vadlamudi RK and Kumar R: Metastasis-associated protein 1 interacts with NRIF3, an estrogen-inducible nuclear receptor coregulator. Mol Cell Biol 24: 6581-6591, 2004.

20. Brahimi-Horn C, Mazure N and Pouyssegur J: Signalling via the hypoxia-inducible factor-1alpha requires multiple posttranslational modifications. Cell Signal 17: 1-9, 2005.

21. Bilton R, Mazure N, Trottier E, Hattab M, Dery MA, Richard DE, Pouyssegur J and Brahimi-Horn MC: Arrest-defective-1 protein, an acetyltransferase, does not alter stability of hypoxia-inducible factor (HIF)-1alpha and is not induced by hypoxia or HIF. J Biol Chem 280: 31132-31140, 2005.

22. Murray-Rust TA, Oldham NJ, Hewitson KS and Schofield CJ: Purified recombinant hARD1 does not catalyse acetylation of Lys(532) of HIF-1alpha fragments in vitro. FEBS Lett (In press).

23. Yoo YG, Kong G and Lee MO: Metastasis-associated protein 1 enhances stability of hypoxia-inducible factor-1alpha protein by recruiting histone deacetylase 1. EMBO J 25: 1231-1241, 2006. 